\title{
Single-cell Motility Analysis of Tethered Human Spermatozoa
}

William M. Skinner ${ }^{1}$, Nadja Mannowetz ${ }^{1}$, Polina V. Lishko ${ }^{1, *}$ and Nadia R. Roan², 3, *

\author{
1Department of Molecular and Cell Biology, University of California, Berkeley, CA, USA; 2Department of \\ Urology, University of California, San Francisco, CA, USA; ${ }^{3}$ Gladstone Institute of Virology and \\ Immunology, San Francisco, CA, USA \\ *For correspondence: Lishko@berkeley.edu; Nadia.roan@ucsf.edu
}

\begin{abstract}
[Abstract] Vigorous sperm flagellar motility is essential for fertilization, and so the quantitative measurement of motility is a useful tool to assess the intrinsic fertility potential of sperm cells and explore how various factors can alter sperm's ability to reach the egg and penetrate its protective layers. Human sperm beat their flagella many times each second, and so recording and accurately quantifying this movement requires a high-speed camera. The aim of this protocol is to provide a detailed description of the tools required for quantitative beat frequency measurement of tethered human sperm at the singlecell level and to describe methods for investigating the effects of intracellular or extracellular factors on flagellar motion. This assay complements bulk measurements of sperm parameters using commerciallyavailable systems for computer-assisted sperm analysis (CASA).
\end{abstract}

Keywords: Human spermatozoa, Sperm motility, High-speed imaging, Single-cell motility analysis, Sperm Swim-up, Sperm flagellum, Seminal plasma, Amyloid fibrils, Flagellar beat frequency

[Background] Sperm motility assessment using beat frequency analysis with the help of high-speed cinemicrography has historically been an important tool to analyze sperm well-being (Katz et al., 1982; Mack et al., 1988). The basal beat frequency (BF) of mammalian spermatozoa varies greatly, with human sperm having one of the highest frequencies-sometimes exceeding $20 \mathrm{~Hz}$ (Smith et al., 2013; Saggiorato et al., 2017)-and many factors are known to affect the BF. These factors can be extracellular, such as the composition of oviductal fluid and seminal plasma, hormones, drugs or environmental toxins, and temperature; or intracellular, like sperm $\mathrm{pH}_{\mathrm{i}}$, calcium concentration $\left(\left[\mathrm{Ca}^{2+}\right]_{i}\right)$, and plasma membrane potential (Turner, 2006; Suarez, 2008). Additionally, as mammalian spermatozoa acquire their full fertilizing potential during their final maturation in the female reproductive tract-a process called capacitation (Austin, 1951; Chang, 1951)-they increase the amplitude and asymmetry of their flagellar waveform, while decreasing their BF. This motility pattern is known as "hyperactivation" (Suarez et al., 1993). Both flagellar wave shape and BF can serve as an important indicator of sperm fertility (White and Aitken, 1989; Uhler et al., 1992; Suarez et al., 1993). While CASA (Computer-Assisted Sperm Analysis) is an excellent and reliable tool widely used in clinics and research laboratories (Cooper and Yeung, 2006; Lu et al., 2014), it is designed to specifically track the motion of the sperm head only and is not reliable to analyze the shape of flagellar motion. In order to accurately count BF and fully resolve the shape of the flagellar motion of human sperm cells, high-speed camera recordings with a frame rate of approximately 1,000 frames per second are required. Here we will describe a method to perform 
frame-by-frame analysis using high-speed camera recordings which can help detect motility defects, assess capacitation state, and evaluate the effects of different treatments on human sperm cells. We describe how the system is set up and use exposure of sperm cells to SEM1(86-107) fibrils (semenderived amyloid fibrils previously shown to enhance HIV infection and participate in excess/defective sperm removal) (Roan et al., 2011 and 2017) as an example of how an exogenous agent can affect sperm motility at the single-cell level.

As with many other human-derived cells, human sperm samples constitute a biosafety hazard. Therefore, all work with such materials should be performed in BSL-2 approved spaces. Moreover, all personnel should be properly trained, including undergoing annual bloodborne pathogen training per institutional guidelines. Lab personnel are also advised to undergo immunization against Hepatitis $B$.

Each human spermatozoon has a head of about $5 \mu \mathrm{m}$ connected to a $45 \mu \mathrm{m}$ tail (flagellum) which is about $0.5 \mu \mathrm{m}$ in diameter (Miller et al., 2018). To observe such a small object, specialized high-resolution optics are required. Using a microscope equipped with Differential Interference Contrast (DIC) or Hoffman Modulation Contrast (HMC) optics is highly recommended over phase-contrast optics since DIC/HMC makes it easier to track the precise motion of the tiny flagellum (Lishko et al., 2013). The measurement rig is composed of an inverted microscope (such as the Olympus IX71 or Nikon Ti series) positioned on a vibration-damping air table and connected to a high-speed camera that can acquire 1,000 frames per second (Figure 1).

It is highly recommended to use an Olympus UPlanSApo 60x water immersion objective or similar lens, with numerical aperture of 1.20. Such an objective features a long working distance $(0.28 \mathrm{~mm})$ and an adjustment collar which can compensate for the thickness of coverslips between 0.13 and $0.21 \mathrm{~mm}$. This combination of long working distance and adjustable collar allows for observations through two $0.13 \mathrm{~mm}$ thickness coverslips: one coverslip serving as a glass bottom of the recording chamber, plus an additional round $5 \mathrm{~mm}$ diameter coverslip placed into the recording chamber, with sperm cells deposited on top. This objective can also allow for observation of free-swimming sperm cells in solution. As will be discussed below, depositing sperm cells on easily exchangeable round $5 \mathrm{~mm}$ diameter coverslips (rather than on the bottom of the recording chamber directly) is a convenient way to load fresh sperm cells into the recording chamber and quickly exchange samples of cells that have been exposed to different conditions. In addition to the $60 x$ objective, inverted microscopes are equipped with 10x eyepieces and an optional 1.6x internal magnification. The regular internal magnification of the microscope (a total of 600x) is used to locate the appropriate sperm cell to record. If higher magnification is needed, the 1.6x internal magnification is engaged for a total of $960 x$.

The assembled rig is positioned on a vibration-damping air table (e.g., Newport or TMC). The absence of any vibration is an essential part of a successful video recording since even a slight vibration will ultimately compromise the recording (Figure 1).

Finally, it is suggested to use a Warner Instruments RC-24E perfusion chamber connected via a manifold to a gravity-fed perfusion system (Figure 2). The RC-24E is a low-volume diamond-shaped chamber with laminar flow and relatively fast solution exchange rates. A round $5 \mathrm{~mm}$ diameter coverslip fits perfectly into the diamond-shape opening of this chamber. To perfuse a solution through the 
recording chamber, a simple self-made gravity-fed perfusion system with a Teflon manifold (Figure 3) allows one to connect the recording chamber to up to 8 separate perfusion lines. It is important to ensure that the tubing used for perfusion of bath solution with human sperm does not leach plasticizers or phthalates into the solutions since such chemicals can significantly alter sperm motility (Fredricsson et al., 1993). A small diameter polytetrafluoroethylene (PTFE, commonly known as Teflon) tubing is highly recommended as the main perfusion tubing. As this tubing is rather stiff, flexible connections are made using high purity silicon tubing that fits over the PTFE tubing (Lishko et al., 2013). In addition, syringes that lack any lubricant (e.g., Air Tite Norm-Ject brand) are strongly recommended for injection of perfusion materials, since mineral oil or other lubricating additives can interfere with sperm ion channels, and hence impair flagellar motility.

\section{Materials and Reagents}

1. Polypropylene sterile sample collection containers (SARSTEDT, catalog number: 75.9922 .745 )

2. Centrifuge Tubes, $50 \mathrm{ml}$ and $15 \mathrm{ml}$ (Olympus Plastics, catalog numbers: 28-106 and 28-101)

3. Positive Displacement Pipettes and Tips (Gilson, MICROMAN)

4. Micropipettes and Tips (Gilson, Pipetman)

5. $5 \mathrm{~mm}$ round coverslips (WPI, catalog number: 502040)

6. $0.22 \mu \mathrm{m}$ Polyethersulfone (PES) Vacuum-Driven Filter System, $500 \mathrm{ml}$ and $1 \mathrm{~L}$ (Olympus Plastics, catalog numbers: $25-227$ and 25-229)

7. MLA Pipette Tips, $200 \mu \mathrm{l}$ (Vista Labs, catalog number: 9025)

8. Osmolarity Calibration Standard (ELITech, OPTIMOLE, catalog number: OA-029)

9. Osmometer Paper Sample Disks (Wescor, VAPRO Sample Disks, catalog number: SS-033)

10. Sodium Chloride ( $\mathrm{NaCl}$ ) (Sigma-Aldrich, catalog number: S7653)

11. Potassium Chloride $(\mathrm{KCl})$ (Fisher Scientific, catalog number: P217)

12. Magnesium Sulfate Heptahydrate $\left(\mathrm{MgSO}_{4} \cdot 7 \mathrm{H}_{2} \mathrm{O}\right)$ (Sigma-Aldrich, catalog number: 63140 )

13. Monopotassium Phosphate $\left(\mathrm{KH}_{2} \mathrm{PO}_{4}\right)$ (Sigma-Aldrich, catalog number: 60216)

14. Calcium Chloride Dihydrate $\left(\mathrm{CaCl}_{2} \cdot 2 \mathrm{H}_{2} \mathrm{O}\right)$ (Sigma-Aldrich, catalog number: 21097$)$

15. HEPES (Fisher Scientific, catalog number: BP310)

16. D-(+)-Glucose $\left(\mathrm{C}_{6} \mathrm{H}_{12} \mathrm{O}_{6}\right)$ (Sigma-Aldrich, catalog number: $\left.\mathrm{G} 8270\right)$

17. Sodium Lactate $\left(\mathrm{C}_{3} \mathrm{H}_{5} \mathrm{NaO}_{3}\right)$ (Sigma-Aldrich, catalog number: $\left.\mathrm{L} 7900\right)$

18. Sodium Pyruvate $\left(\mathrm{C}_{3} \mathrm{H}_{3} \mathrm{NaO}_{3}\right)$ (Sigma-Aldrich, catalog number: $\left.\mathrm{P} 2256\right)$

19. Sodium Hydroxide $(\mathrm{NaOH})$ (Sigma-Aldrich, catalog number: 221465$)$

20. Sodium Bicarbonate $\left(\mathrm{NaHCO}_{3}\right)$ (Sigma-Aldrich, catalog number: S5761)

21. Fetal Bovine Serum (FBS) (Gibco, catalog number: 16000036)

22. Hydrochloric Acid $(\mathrm{HCl})$ (Fisher Scientific, catalog number: A144S)

23. Human fibrillogenic peptide SEM1(86-107) (Celtek and CPC Scientific, sequence: DLNALHKTTKSQRHLGGSQQLL)

24. pH 4.0 Standard, Red (EMD Chemicals, catalog number: BX1628-1) 
25. pH 7.00 Standard, Yellow (Fisher Scientific, catalog number: SB107-500)

26. $\mathrm{pH} 10.00$ Standard, Blue (Fisher Scientific, catalog number: SB115-500)

27. Phosphate-Buffered Saline (PBS) (Fisher Scientific, catalog number: BP665-1)

28. $70 \%$ Ethanol (Decon Labs, catalog number: V1001)

29. Human Tubal Fluid (HTF) Solution (see Recipes)

30. High-Saline solution (HS) (see Recipes)

31. Capacitation media (see Recipes)

32. Motility disrupting reagents and control reagents (see Recipes)

\section{Equipment}

A. General

1. Incubator (Fischer Scientific, Isotemp Incubator)

2. $\mathrm{CO}_{2}$ Incubator (for capacitation) (Eppendorf, Galaxy 170S, catalog number: C017101001)

3. Water Filter (Millipore, Milli-Q, Advantage, catalog number: A10-TOC)

4. Balances (Mettler Toledo, models: XS2002S and XS105)

5. $\mathrm{pH}$ Meter (Denver Instruments, Ultra Basic UB-10)

6. Vapor Pressure Osmometer (Wescor, model 5600)

7. $10 \mu \mathrm{l}$ Fixed volume MLA pipette (Vista Labs, catalog number: 1051C)

8. Forceps (Excelta, catalog number: 5-S-SE)

9. Thermomixer (Eppendorf) for generation of semen amyloid fibrils

10. $4{ }^{\circ} \mathrm{C}$ refrigerator

11. Hemacytometer (Hausser Scientific, Reichert Bright-Line, catalog number: 1483)

12. Slanted Tube Rack for $50 \mathrm{ml}$ Tubes (Bel-Art, catalog number: F18794-0028)

B. Microscopy (Figure 1)

1. Inverted microscope (Olympus, model: IX-71)

2. Water immersion objective (Olympus, UPlanSApo, $60 \mathrm{x}, 1.20 \mathrm{~W}, \infty / 0.13-0.21 / \mathrm{FN} 26.5$, catalog number: UPLSAPO 60XW)

3. Digital high-speed camera (NAC Image Technology, Memrecam GX-1 or similar type of highspeed camera)

4. Light source (Olympus, $100 \mathrm{~W}$ halogen lamp housing U-LH100L-3 with lamp 12V100WHAL)

5. Light source power supply (Olympus, catalog number: TH4-100)

6. Vibration Isolation Table (Newport, Vision IsoStation)

7. Recording chamber (Warner Instruments, RC-24E); A rectangular coverslip (Corning, $24 \times 40$ mm Rectangular \#1 Cover Glass, thickness $.13 \mathrm{~mm}$, catalog number: 2975-244) is glued to the bottom of the chamber with SYLGARD 184 (Dow Corning, Midland, MI) according to the manufacturer's instructions. Grease is not recommended since it can leach into the chamber and alter the physiological properties of sperm cells. 
C. Perfusion and Suction (Figures 2 and 3)

1. Teflon 8-position perfusion manifold (Warner Instruments, MP-8, catalog number: 64-0211)

2. Suction control (B. Braun, Exadrop, Germany)

3. Suction tube (Warner Instruments, ST-QE1, catalog number: 64-1403)

4. Magnetic clamps for suction tube (Warner Instruments, MAG-1, catalog number: 64-0358; and MAG-7, catalog number: 64-1554)

5. Polytetrafluoroethylene (PTFE) perfusion tubing (Microbore PTFE Tubing, 0.022" ID x 0.042" OD) (Cole-Parmer, catalog number: EW-06417-21)

6. Silicone Connector Tubing (Platinum-Cured Silicone Tubing, 1/32" ID x 3/32" OD) (Cole-Parmer, catalog number: EW-95802-01)

7. Manifold Connector Tubing (PTFE Tubing, 1/32" ID x 1/16" OD) (Cole-Parmer, catalog number: EW-06407-41)

8. Stopcock with Luer Connections; 4-way; Male Lock (Cole-Parmer, catalog number: EW-3060009)

9. Female Luer Hose Barb Adapter, 1/16" (Cole-Parmer, catalog number: EW-45508-00)

10. Syringes (Air-Tite, Norm-Ject Luer Lock Syringe, catalog number: AL20 and AL3)

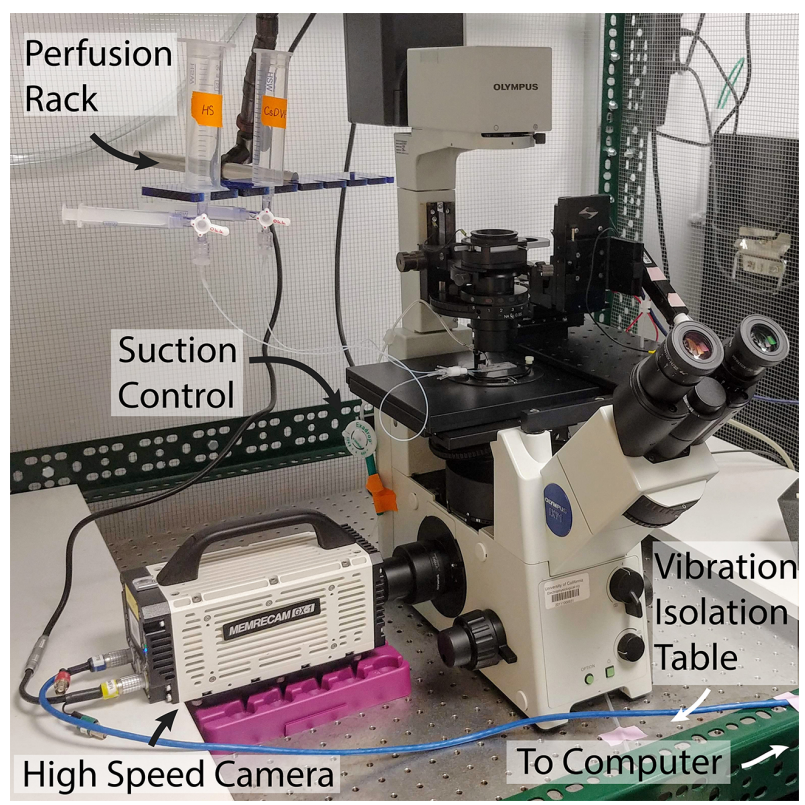

Figure 1. Fully assembled high-speed video microscopy rig with perfusion setup, on a vibration-isolation table 


\section{biö-protocol



Figure 2. Assembled perfusion chamber for recording. A. The recording chamber is placed inside the stage adapter and connected to perfusion lines via a perfusion manifold. The suction line is attached to a metal suction tube, which is positioned on the stage adapter with a magnetic clamp. B. Top view of the same setup.



Figure 3. Homemade perfusion line. The large syringe is used to hold perfusion fluid, and the small syringe is used to purge air bubbles from the system. The Perfusion Manifold allows for up to 8 perfusion lines to be connected simultaneously. Extra manifold ports are blocked when not in use.

\section{Software}

1. Memrecam GXLink software, version 3.20 (NAC Image Technology)

2. ImageJ version 1.44 (http://rsb.info.nih.gov/ij/)

3. Statistical Analysis Software (OriginLabs, Origin, or equivalent) 


\section{Procedure}

A. Sperm collection and purification-"Swim-up"

1. Obtain approval from your organization's Institutional Review Board to conduct studies involving human subjects. Recruit healthy male volunteers of reproductive age older than 21 years to provide semen samples. Freshly ejaculated semen samples should be collected by masturbation into sterile polypropylene sample containers. Ensure that the sample containers chosen are clear of plasticizers, which can negatively affect sperm quality. Advise donors to avoid sexual activity for 3 days before collecting a sample. Ask donors to record the time of collection, and to deliver the sample to the lab within $30 \mathrm{~min}$ of collection. (Figure 4)

2. The human ejaculate sample should be left at room temperature for 30-60 $\mathrm{min}$ from the time of collection to allow it to gradually become less viscous (through the action of seminal proteases). This eases pipetting of the semen and ensures complete release of sperm cells from the seminal plasma, which contains sperm-binding proteins such as semenogelins. However, it is essential to start the "swim-up" (Step A4 and Figure 4) within $1 \mathrm{~h}$ after collection to prevent the seminal proteases from damaging the sperm cells.



Figure 4. Semen sample and tubes of HTF fluid. The semen sample is in the collection container at right. The donor's anonymized identity number and time of collection is labeled on the collection container (but redacted for publication). One $\mathrm{ml}$ of semen will be underlaid into each of the tubes of HTF on the left. In this case, only 3 tubes of HTF were used, as the ejaculate volume was roughly $3 \mathrm{ml}$.

3. Add $7 \mathrm{ml}$ of HTF (Human Tubal Fluid) solution to a $50 \mathrm{ml}$ centrifuge tube and warm it to approximately $37^{\circ} \mathrm{C}$ in the incubator. Visually assess the volume of the ejaculate-if the volume is greater than $1 \mathrm{ml}$, prepare multiple tubes of HTF solution (Figure 4).

4. Once the HTF is warm, carefully underlay $1 \mathrm{ml}$ of liquefied ejaculate to the bottom of each tube (Figure 5). Use of a positive displacement pipette greatly facilitates this process. Avoid agitating the semen, or introducing bubbles, which can lift strands of semen to the surface of the HTF 
buffer. If strings of semen persist when removing the pipette from the semen sample, more liquification time is needed.



Figure 5. Semen sample before and after swim-up. A. HTF fluid in falcon tube before addition of semen. B. One $\mathrm{ml}$ of semen carefully underlaid at the bottom of the tube. C. The same tube after $1 \mathrm{~h}$ of incubation at $37^{\circ} \mathrm{C}$. Note the supernatant is cloudier, and the boundary between the semen and the HTF fluid less defined. This shows that sperm has swum up into the supernatant. D. The same tube after removing several milliliters of supernatant.

5. Place the tubes in a $37^{\circ} \mathrm{C}$ incubator for $1 \mathrm{~h}$, in a stand that holds them at a $45^{\circ}$ angle, in order to increase the surface area for swim-up. If the incubator is a $\mathrm{CO}_{2}$ incubator, close the cap tightly to prevent acidification of buffer- $-\mathrm{CO}_{2}$ is not required for this procedure. During this incubation, motile sperm will gradually swim out of the semen sample and up into the HTF supernatant, thereby cleansing themselves of most residual seminal proteins. Purifying human spermatozoa using this "swim-up" technique avoids sperm damage induced by the G-forces of the centrifugation used in other purification procedures (Figure 5).

6. After $1 \mathrm{~h}$, the supernatant should contain only motile sperm. Carefully collect about $2-3 \mathrm{ml}$ of the supernatant from each tube, merging the supernatant from all HTF tubes into a single separate $15 \mathrm{ml}$ conical tube (Figures 5 and 6). The most motile sperm are found in the upper sections of the supernatant, so to gather only highly motile sperm, pipette from near the surface of the supernatant. To avoid gathering any seminal plasma, do not attempt to remove all of the supernatant-leave several milliliters of HTF remaining above the seminal plasma. Discard HTF and semen tubes after removal of supernatant.

7. Let the $15 \mathrm{ml}$ tube stand vertically for about $30-60 \mathrm{~min}$ at RT. Spermatozoa will concentrate at the bottom (where a white cloud will form) as they gradually become less motile due to HTF solution's relatively low sodium concentration. When submersed in HS solution (which has a higher sodium concentration) these sperm cells will resume their aggressive motility (Figure 6). 


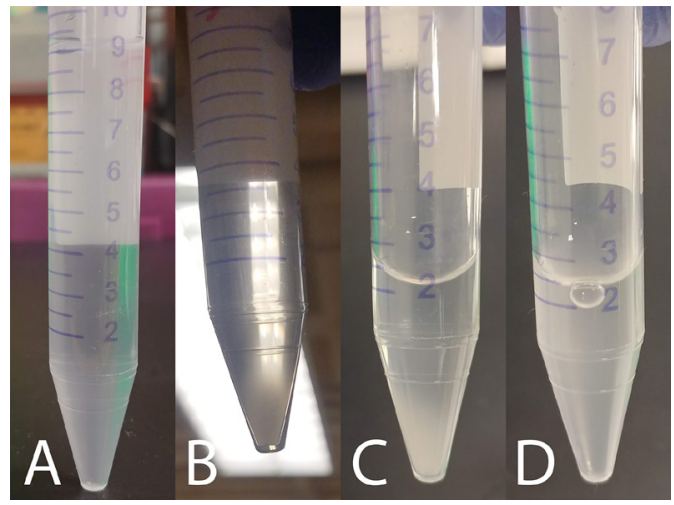

Figure 6. Sperm settling and concentration. A. Three $\mathrm{ml}$ of HTF supernatant was removed from each swim-up tube and pooled into one $15 \mathrm{ml}$ conical tube. B. The cloud of sperm cells that have settled to the bottom of the tube after 30-60 min standing at RT. C. Several milliiters of supernatant removed to concentrate the sperm cells. D. Sperm cloud resuspended by gentle pipetting.

8. Remove the supernatant from the tube to concentrate the cells, and gently resuspend the cloud of cells in the remaining HTF solution (Figure 6). A normal ejaculate should contain at least $15 \times 10^{6}$ sperm cells per $\mathrm{ml}$ (WHO, 2010), but sperm counts vary widely between different samples, so technicians will need to develop an intuition of how much supernatant to leave in the tube, based on the size of the sperm cloud, in order to reach the desired concentration of cells. If cell concentration is outside of the desired range in downstream applications, the technician can use more or less of this sperm solution, or if needed, dilute it with more HTF or allow the cells to settle again and remove additional supernatant.

9. Take an aliquot of the sperm suspension and determine the cell concentration using a hemacytometer.

B. Recording high-speed video of sperm motility

1. Place a $5 \mathrm{~mm}$ diameter coverslip in the main diamond-shaped well of the recording chamber. Then fill the recording chamber with $\sim 300 \mu \mathrm{l}$ of room temperature HS solution, making sure that all wells (including the main well and the suction wells) have liquid in them, and that no air bubbles are blocking the covered connection lane between the front and back wells. Ensure that the coverslip is fully submerged and flat on the bottom of the recording chamber, with no bubbles underneath it, by tapping it down with a pipette tip or forceps.

2. Take $20-50 \mu \mathrm{l}$ of the concentrated sperm cell suspension from the storage tube, and gently add it to the HS solution above the coverslip. Although spermatozoa are motile, many will accumulate on the surface of the coverslip, where their heads will adhere electrostatically, while their flagella will vigorously beat in the solution just above the coverslip. Allow sperm cells to sediment onto the coverslip for 10-30 min at room temperature.

3. If capacitated cells are needed, first allow cells to adhere to the coverslip, then perfuse the recording chamber with capacitation media and incubate cells at $37{ }^{\circ} \mathrm{C}$ for $4 \mathrm{~h}$ in a $5 \% \mathrm{CO}_{2}$ 
incubator (Lishko et al., 2010). It is essential to use $\mathrm{a} \mathrm{CO}_{2}$ incubator at this step as capacitation media contains sodium bicarbonate, which together with atmospheric $\mathrm{CO}_{2}$ maintains the required $\mathrm{pH}$ during the capacitation process. It is recommended to adhere the cells before adding capacitation media because the FBS in the capacitation media makes the sperm adhere less strongly to the coverslip.

4. With the microscope in Differential Interference Contrast mode, add a $\sim 50 \mu \mathrm{l}$ droplet of water directly onto the $60 x$ objective, place the recording chamber into the stage adapter and mount the adapter on the microscope stage, then put the perfusion and suction lines into place, as shown in Figure 2. Then turn the light source on and find the correct focal plane for the upper surface of the coverslip. It is often helpful to do this by first finding an edge of the coverslip and then gradually adjusting the focal plane upwards-you will first encounter the glass bottom of the recording chamber, then the lower surface of the coverslip, then the upper surface of the coverslip.

5. At this point, it is often useful to turn on HS perfusion to remove debris and excess spermatozoa from the recording chamber. For capacitated sperm, one must avoid turning on perfusion immediately after a fresh coverslip is placed into the perfusion chamber to ensure that the largest number of capacitated spermatozoa are attached and available for analysis. In this case, after the appropriate cell is chosen and recorded, the perfusion can be turned on. Ensure that the HS solution in the syringe has reached room temperature $\left(\sim 24^{\circ} \mathrm{C}\right)$ before starting perfusion. If incubation at a warmer temperature is required, you may place the recording chamber and stage adapter into the incubator, or use a built-in electrical heater in the stage adapter or incorporated into the perfusion line.

6. Assess the sperm cells for strict morphology, overall motility, and concentration using WHO guidelines (WHO, 2010). Morphologically normal sperm cells (Kruger et al., 1987) can then be sampled for movement analysis. Morphological abnormalities of sperm include vacuolated, round, amorphous, tapering, pyriform, megalocephalic or microcephalic heads; asymmetrical, bent or thin midpiece; and various tail defects. Sperm motility should always be confirmed and recorded before any motility-altering drug/compound treatment is administered.

7. Once appropriate cells are identified, switch the optical routing to the camera mode, and activate the camera to record video. It is useful to find a field of view with enough sperm cells to allow for multiple measurements from the same video, but for accurate measurements, assess cells whose flagella do not overlap with other nearby cells. Gain, frame rate, and many other recording settings can be adjusted in the GXLink software. We use a frame rate of 1,000 frames per second to facilitate beat frequency calculations since 1 frame then corresponds to an interval of approximately $1 \mathrm{~ms}$.

8. Once video has been captured of control cells, perfuse or pipette in treatment compounds (e.g., $50 \mu \mathrm{g} / \mathrm{ml}$ SEM1(86-107) fibrils or the corresponding monomeric peptide control), wait $10 \mathrm{~min}$, and then record additional videos. After all needed video has been recorded, carefully remove the coverslip from the recording chamber with forceps, and then discard it. If treatment with 
several different compounds is required, cells can also be seeded onto coverslips and incubated simultaneously in separate wells of a cell-culture dish, then each coverslip can be carefully transferred one at a time into the recording chamber for imaging. Ensure that the cells remain covered with liquid at all times.

Once all needed recordings have been made, remove the coverslip from the recording chamber, aspirate the remaining solution in the recording chamber, and clean by rinsing it with water and $70 \%$ ethanol, followed by a triple rinse with deionized water (18 $\mathrm{M} \Omega)$. Avoid prolonged exposure of the chamber plastic to alcohols. The chamber can be reused indefinitely.

\section{Data analysis}

1. Videos recorded in the GXLink software can be exported in a variety of formats. For quantitative analysis, export the movie as a series of images in 8-bit TIFF format.

2. Import these TIFF files as an image stack in ImageJ. Use the marker tool to mark a point touching the edge of a sperm's flagellum, near the midpiece, when it is at its maximum displacement from center. Then scroll through the images until the flagellum touches that marker again (Figure 7). The number of frames between the two touches of the marker point represents the Period $(\mathrm{T})$, in milliseconds, which is the time required to complete one full flagellar stroke (if the frames were collected at 1,000 frames per second, where 1 frame equals $1 \mathrm{~ms}$ ). Since Beat Frequency (BF) is measured in $\mathrm{Hz}$, use the following equation to determine $\mathrm{BF}$ of the sperm tail:

$$
B F=\frac{1000}{T}
$$

Collect frequency measurements for a statistically appropriate number of cells, and evaluate the data with the statistical analysis software of your choice.

3. To quantitate the effects of SEM1(86-107) fibrils or other agents on motility, BFs are calculated twice: first prior to perfusion of the agent, and then $10 \mathrm{~min}$ after the perfusion. 


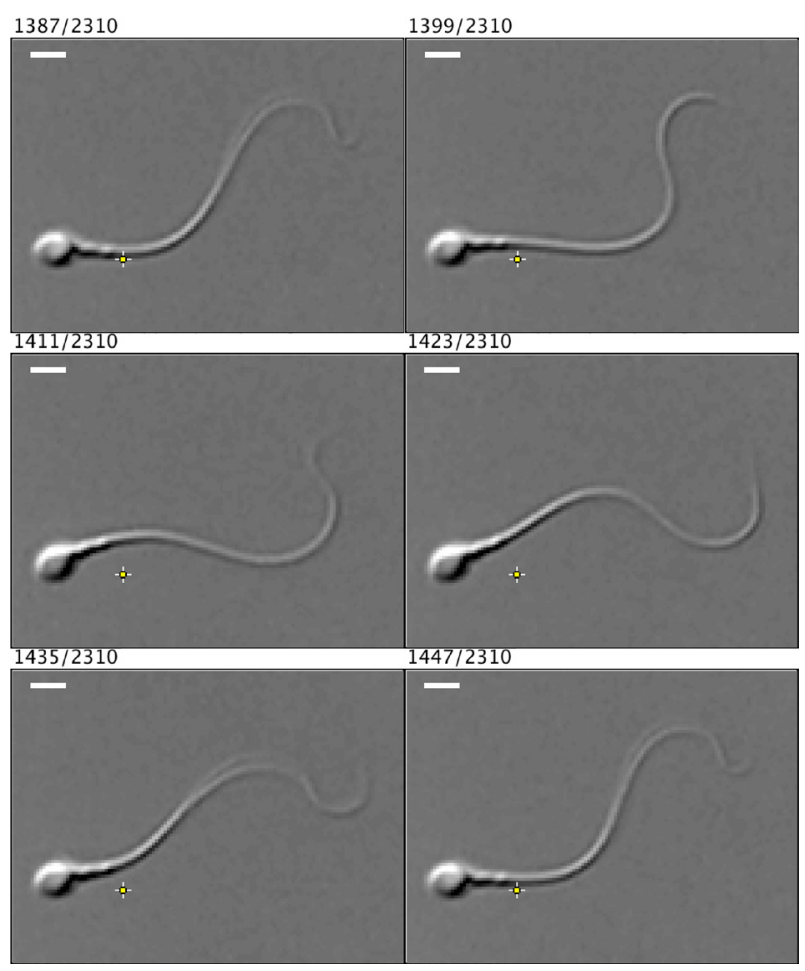

Figure 7. Example frames illustrating the measurement of one full beat cycle of a human spermatozoa. The numbers above each frame indicate specific frame position out of 2,310 frames collected. There is a 12 -frame gap between each image displayed here, and the scale bars represent approximately $5 \mu \mathrm{m}$. The image was contrast enhanced in ImageJ for visual clarity. This spermatozoon has a period of $60 \mathrm{~ms}$, and therefore a frequency of approximately $17 \mathrm{~Hz}$. Video (.avi) and TIFF files are included as supplemental materials.

\section{$\underline{\text { Notes }}$}

1. Once high-speed images have been captured, various methods exist to evaluate the beat frequency. In addition to the method described here, it is possible to choose a time window (e.g., $0.5 \mathrm{~s}$ or $1 \mathrm{~s}$ ) and measure how many full beats are completed in this time window, then mathematically scale that number to beats per second (Roan et al., 2017). Others have used custom computer image analysis software to trace the pattern of flagellar motion and fit sinusoidal curves to it, or Fast Fourier Transform analysis to report beat frequency directly from the power spectrum of the intensity changes along a line scan perpendicular to the flagellar beat axis (Wennemuth et al., 2003; Burnett et al., 2010; Saggiorato et al., 2017; Muschol et al., 2018).

2. Beat Frequency (BF) should not be confused with Beat Crossing Frequency (BCF) as reported by CASA systems, which is defined as the number of times the sperm head crosses the direction of movement of the free-swimming cell (Mortimer, 2000). Due to the sinusoidal nature of tethered flagellar motion, the BCF will generally be twice as large as the BF. 
3. When mammalian spermatozoa are free-swimming, rather than tethered, their flagella move in all three dimensions, resulting in a roughly helical path, which complicates beat frequency analysis (Muschol et al., 2018).

\section{$\underline{\text { Recipes }}$}

1. Human Tubal Fluid (HTF) Solution

\begin{tabular}{|c|c|c|c|c|}
\hline \multirow[t]{2}{*}{ Substance } & \multirow{2}{*}{$\begin{array}{ll}\text { Molar } & \text { mass } \\
(\mathrm{g} / \mathrm{mol}) & \end{array}$} & \multirow{2}{*}{$\begin{array}{l}\text { Final concentration } \\
(\mathrm{mM})\end{array}$} & \multicolumn{2}{|l|}{ Weight } \\
\hline & & & For $500 \mathrm{ml}$ & For $1,000 \mathrm{ml}$ \\
\hline $\mathrm{NaCl}$ & 58.44 & 97.8 & $2.86 \mathrm{~g}$ & $5.72 \mathrm{~g}$ \\
\hline $\mathrm{KCl}$ & 74.55 & 5 & $0.186 \mathrm{~g}$ & $0.373 \mathrm{~g}$ \\
\hline $\mathrm{MgSO}_{4} \cdot 7 \mathrm{H}_{2} \mathrm{O}$ & 246.48 & 0.2 & $24.6 \mathrm{mg}$ & $49.3 \mathrm{mg}$ \\
\hline $\mathrm{KH}_{2} \mathrm{PO}_{4}$ & 136.09 & 0.37 & $25.2 \mathrm{mg}$ & $50.4 \mathrm{mg}$ \\
\hline $\mathrm{CaCl}_{2} \cdot 2 \mathrm{H}_{2} \mathrm{O}$ & 147.02 & 2 & $0.147 \mathrm{~g}$ & $0.294 \mathrm{~g}$ \\
\hline HEPES & 238.31 & 28 & $3.336 \mathrm{~g}$ & $6.673 \mathrm{~g}$ \\
\hline $\begin{array}{l}\text { Sodium } \text { Lactate } \\
\text { Solution } \quad(60 \% \\
\text { w/w })\end{array}$ & 112.06 & 20 & $1.5 \mathrm{ml}$ & $3 \mathrm{ml}$ \\
\hline $\begin{array}{l}\text { Sodium } \\
\text { Pyruvate }\end{array}$ & 110 & 0.4 & $22 \mathrm{mg}$ & $44 \mathrm{mg}$ \\
\hline Glucose & 180.2 & 3 & $0.270 \mathrm{~g}$ & $0.540 \mathrm{~g}$ \\
\hline
\end{tabular}

a. Adjust $\mathrm{pH}$ to 7.3-7.4 with $\mathrm{NaOH}$. Osmolarity should be $280 \pm 5 \mathrm{mOsm}$, measured using a Vapor Pressure Osmometer

b. Filter through a sterile $0.2 \mu \mathrm{m}$ PES filter and store the final solution at $4{ }^{\circ} \mathrm{C}$ for up to one month. Sodium lactate solution is used instead of lactic acid due to sodium lactate's greater stability and manufacturing consistency

2. High-Saline (HS) Solution

\begin{tabular}{|l|l|l|l|l|}
\hline Substance & $\begin{array}{l}\text { Molar mass } \\
(\mathrm{g} / \mathrm{mol})\end{array}$ & $\begin{array}{l}\text { Concentration } \\
(\mathrm{mM})\end{array}$ & \multicolumn{2}{l}{ Weight $(\mathrm{g})$} \\
\cline { 4 - 5 } & & & \multicolumn{2}{l}{} \\
\hline $\mathrm{NaCl}$ & 58.44 & 135 & $3.945 \mathrm{~g}$ & $7.889 \mathrm{~g}$ \\
\hline $\mathrm{KCl}$ & 74.56 & 5 & $0.186 \mathrm{~g}$ & $0.373 \mathrm{~g}$ \\
\hline $\mathrm{CaCl}_{2} \cdot 2 \mathrm{H}_{2} \mathrm{O}$ & 147.02 & 2 & $0.147 \mathrm{~g}$ & $0.294 \mathrm{~g}$ \\
\hline $\mathrm{MgSO}_{4} \cdot 7 \mathrm{H}_{2} \mathrm{O}$ & 246.48 & 1 & $0.123 \mathrm{~g}$ & $0.247 \mathrm{~g}$ \\
\hline $\mathrm{HEPES}$ & 238.3 & 20 & $2.383 \mathrm{~g}$ & $4.766 \mathrm{~g}$ \\
\hline Glucose & 180.2 & 5 & $0.451 \mathrm{~g}$ & $0.901 \mathrm{~g}$ \\
\hline $\begin{array}{l}\text { Sodium } \\
\text { Solution } \\
\text { w/w })\end{array}$ & 112.06 & 10 & $0.75 \mathrm{ml}$ & $1.5 \mathrm{ml}$ \\
\hline Sodium Pyruvate & 110 & & & \\
\hline
\end{tabular}


a. Adjust $\mathrm{pH}$ to 7.3-7.4 with $\mathrm{NaOH}$. Osmolarity should be $320 \pm 5 \mathrm{mOsm}$, measured using a Vapor Pressure Osmometer

b. Filter through a sterile $0.2 \mu \mathrm{m}$ PES filter and store the final solution at $4{ }^{\circ} \mathrm{C}$ for up to one month. Sodium lactate solution is used instead of lactic acid due to sodium lactate's greater stability and manufacturing consistency

3. Capacitation media (Lishko et al., 2010) In premade $\mathrm{HS}$ solution, add $20 \%$ Fetal Bovine Serum and $25 \mathrm{mM} \mathrm{NaHCO}_{3}$

Note: Capacitation media must be prepared freshly before each use and used within the same day.

4. Motility disrupting reagents and control reagents

a. Human fibrillogenic peptide SEM1(86-107) (Sequence: DLNALHKTTKSQRHLGGSQQLL) was custom-synthesized by a commercial vendor (Celtek and CPC Scientific) but can also be synthesized in-house. Peptide purity should be $>95 \%$. The peptide can be dissolved at a concentration of $2.5 \mathrm{mg} / \mathrm{ml}$ in PBS ( $\mathrm{pH} 7.0)$. This peptide serves as the monomeric peptide (negative) control and does not restrict sperm motility

b. To generate amyloid fibrils, the $2.5 \mathrm{mg} / \mathrm{ml}$ SEM1(86-107) peptide is agitated in $100 \mu \mathrm{l}$ aliquots for $12 \mathrm{~h}$ at $37^{\circ} \mathrm{C}$ at $1,400 \mathrm{rpm}$ in an Eppendorf Thermomixer, after which the solution should look turbid as a result of fibril formation

c. Fibril formation can be confirmed by thioflavin T binding or electron microscopy (Roan et al., 2011)

d. We have previously found that cationic fibrils from semen [SEM1(86-107) fibrils, SEVI fibrils, and Galago repeat fibrils] entrapped sperm cells, while monomeric peptides [unagitated SEM1(86-107), SEM1(68-85) and SEM1(108-159)] and non-cationic fibrils [Aß(1-42)] did not (Roan et al., 2017)

\section{Acknowledgments}

This work was supported by NIH grants R21Al116252 and R21Al122821 to N.R.R, and by R01GM111802, Pew Biomedical Scholars Award, and Packer Wentz Endowment Will to P.V.L. The authors would like to thank Dr. Donner F. Babcock for his valuable suggestions and comments, and to Emiliano Tabarsi for his technical assistance.

\section{Competing interests}

We declare there are no competing interests. 


\section{Ethics}

This study was conducted with the approval of the Committee on Human Research at the University of California, Berkeley (CPHS protocol \#2013-06-5395; issued under University of California, Berkeley Federalwide Assurance \#00006252).

\section{References}

1. Austin, C. R. (1951). Observations on the penetration of the sperm in the mammalian egg. Aust J Sci Res B 4(4): 581-596.

2. Burnett, L. A., Blais, E. M., Unadkat, J. D., Hille, B., Tilley, S. L. and Babcock, D. F. (2010). Testicular expression of Adora3i2 in Adora3-knockout mice reveals a Role of mouse A3Ri2 and human A3Ri3 adenosine receptors in sperm. J Biol Chem 285: 33662-33670.

3. Chang, M. C. (1951). Fertilizing capacity of spermatozoa deposited into the fallopian tubes. Nature 168(4277): 697-698.

4. Cooper, T. G. and Yeung, C. H. (2006). Computer-aided evaluation of assessment of "grade a" spermatozoa by experienced technicians. Fertil Steril 85(1): 220-224.

5. Fredricsson, B., Möller, L., Pousette, A. and Westerholm, R. (1993). Human sperm motility is affected by plasticizers and diesel particle extracts. Pharmacol Toxicol 72(2): 128-133.

6. Katz, D. F., Diel, L. and Overstreet, J. W. (1982). Differences in the movement of morphologically normal and abnormal human seminal spermatozoa. Biol Reprod 26(4): 566570.

7. Kruger, T. F., Acosta, A. A., Simmons, K. F., Swanson, R. J., Matta, J. F., Veeck, L. L., Morshedi, M. and Brugo, S. (1987). New method of evaluating sperm morphology with predictive value for human in vitro fertilization. Urology 30(3): 248-251.

8. Lishko, P. V., Botchkina, I. L., Fedorenko, A. and Kirichok, Y. (2010). Acid extrusion from human spermatozoa is mediated by flagellar voltage-gated proton channel. Cell 140(3): 327-337.

9. Lishko, P. V., Clapham, D. E., Navarro, B. and Kirichok, Y. (2013). Sperm patch-clamp. Methods Enzymol 525: 59-83.

10. Lu, J. C., Huang, Y. F. and Lü, N. Q. (2014). Computer-aided sperm analysis: past, present and future. Andrologia 46: 329-338.

11. Mack, S. O., Wolf, D. P. and Tash, J. S. (1988). Quantitation of specific parameters of motility in large numbers of human sperm by digital image processing. Biol Reprod 38(2): 270-281.

12. Miller, M. R., Kenny, S. J., Mannowetz, N., Mansell, S. A., Wojcik, M., Mendoza, S., Zucker, R. S., Xu, K. and Lishko, P. V. (2018). Asymmetrically positioned flagellar control units regulate human sperm rotation. Cell Rep 24: 2606-2613.

13. Mortimer, S. T. (2000). CASA--practical aspects. J Androl 21(4): 515-524. 
14. Muschol, M., Wenders, C. and Wennemuth, G. (2018). Four-dimensional analysis by highspeed holographic imaging reveals a chiral memory of sperm flagella. PLoS One 13(6): e0199678.

15. Roan, N. R., Muller, J. A., Liu, H., Chu, S., Arnold, F., Sturzel, C. M., Walther, P., Dong, M., Witkowska, H. E., Kirchhoff, F., Munch, J. and Greene, W. C. (2011). Peptides released by physiological cleavage of semen coagulum proteins form amyloids that enhance HIV infection. Cell Host Microbe 10(6): 541-550.

16. Roan, N. R., Sandi-Monroy, N., Kohgadai, N., Usmani, S. M., Hamil, K. G., Neidleman, J., Montano, M., Standker, L., Rocker, A., Cavrois, M., Rosen, J., Marson, K., Smith, J. F., Pilcher, C. D., Gagsteiger, F., Sakk, O., O'Rand, M., Lishko, P. V., Kirchhoff, F., Munch, J. and Greene, W. C. (2017). Semen amyloids participate in spermatozoa selection and clearance. Elife 6: e24888.

17. Saggiorato, G., Alvarez, L., Jikeli, J. F., Kaupp, U. B., Gompper, G. and Elgeti, J. (2017). Human sperm steer with second harmonics of the flagellar beat. Nat Commun 8(1): 1415.

18. Smith, J. F., Syritsyna, O., Fellous, M., Serres, C., Mannowetz, N., Kirichok, Y. and Lishko, P. V. (2013). Disruption of the principal, progesterone-activated sperm $\mathrm{Ca}^{2+}$ channel in a CatSper2deficient infertile patient. Proc Natl Acad Sci U S A 110(17): 6823-6828.

19. Suarez, S. S. (2008). Control of hyperactivation in sperm. Hum Reprod Update 14: 647-657.

20. Suarez, S. S., Varosi, S. M. and Dai, X. (1993). Intracellular calcium increases with hyperactivation in intact, moving hamster sperm and oscillates with the flagellar beat cycle. Proc Natl Acad Sci U S A 90(10): 4660-4664.

21. Turner, R. M. (2006). Moving to the beat: a review of mammalian sperm motility regulation. Reprod Fertil Dev 18: 25.

22. Uhler, M. L., Leung, A., Chan, S. Y. and Wang, C. (1992). Direct effects of progesterone and antiprogesterone on human sperm hyperactivated motility and acrosome reaction. Fertil Steril 58(6): 1191-1198.

23. Wennemuth, G., Babcock, D. F. and Hille, B. (2003). Calcium clearance mechanisms of mouse sperm. J Gen Physiol 122(1): 115-128.

24. White, D. R. and Aitken, R. J. (1989). Relationship between calcium, cyclic AMP, ATP, and intracellular $\mathrm{pH}$ and the capacity of hamster spermatozoa to express hyperactivated motility. Gamete Res 22(2): 163-177.

25. World Health Organization, Department of Reproductive Health and Research. (2010). World health organization laboratory manual for the examination and processing of human semen. 5 th edition. 